\title{
A dynamic leader-follower model based on lack of central authority in emergency situations
}

\author{
Fatemeh Delkhosh ${ }^{\mathbf{a}^{*}}$
}

${ }^{a}$ Department of Industrial Engineering, Iran University of Science and Technology, Tehran, Iran

CH R O N I L E A B S T R A C T

Article history:

Received: August 1, 2019

Received in revised format: $\mathrm{Au}$ gust 1, 2019

Accepted: August 28, 2019

Available online: August 28, 2019

Keywords:

Multi-level programing

Humanitarian logistics

Multi-objective optimization

Disaster management

\begin{abstract}
Most of the time, the government of the affected country cannot handle the entire relief operations. Under such conditions, international organizations act independently but are obliged to obey the law of the country. In this paper, we propose a dynamic multi-level programming where the affected country and international organizations dynamically change their roles, being leader or follower, according to a game. The application of the proposed model is investigated for a case problem where real data are utilized to design a network for humanitarian logistics during potential earthquakes. The advantages of using multi-level modeling against considering just one player's point of view are provided to guide decision-makers under a variety of conditions. The results show for the first three periods, the government of the affected area cannot handle the demand for the rescue operation. Thus, the international suppliers act as the leader for the first three periods. However, by decreasing the demand for the rescue operation in the last three periods, the government can manage the evacuation operation properly.
\end{abstract}

\section{Introduction}

Series of events that represent critical threat to the health, safety, security, or well-being of a community or other large group of people, usually over a wide area is called humanitarian crises. Note that there are no universally recognized definitions for humanitarian crises. For example, according to Kress (2016), prolonged situations such as famine, or uncontemplated conditions such as earthquake and fatal diseases are known as a humanitarian crisis. In this paper, we mainly focus on the humanitarian crisis that resulted from an earthquake. Earthquake is defined as one of the most hazardous disasters, which usually leads to widespread destruction and human injuries. The world's largest earthquake with an instrumentally documented magnitude occurred on May 22, 1960, near Valdivia, in southern Chile. It was assigned a magnitude of 9.5 by the United States Geological Survey. The Chilean government estimated that approximately 6000 lost their lives, and about 2,000,000 people were left homeless. Furthermore, the costs of the damage were estimated to have been between $\$ 400$ and $\$ 800$ million in 1960 dollars, which would be about $\$ 3$ to $\$ 6$ billion today, adjusted for inflation. A magnitude 6.5 earthquake devastated the small

* Corresponding author.

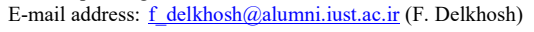


city of Bam in southeast Iran on December 26, 2003 and claimed at least 40,000 lives. On January 12, 2010, an earthquake with magnitude 7.0 happened in Haiti. According to official estimates, more than 200,000 people were killed, 300,000 were injured, and 1.3 million displaced. These are only a few examples of the worst earthquakes in Earth's history. Statistics show that earthquakes affect more than 300 million people every year (Fereiduni \& Shahanaghi, 2017). Human loss is the primary concern in the presence of natural disasters. However, the financial damage of such occurrences is undeniable. According to EMDAT, in 2011, global damage costs from natural disasters was more than $\$ 350$ billion. In 2016, in China and the U.S. the total damage of natural disasters were more than $\$ 70$ and $\$ 65$ billion, respectively (Guha-Sapir et al., 2011). Both human and financial loss resulted from natural disasters led scholars to come up with a branch in management called disaster management. In 1980s, the first steps to mathematically formulate marine disasters were taken (Fereiduni \& Shahanaghi, 2016). Humanitarian logistics received a lot of attention right after starting the twenty-first century. In 2004, after the Indian Ocean tsunami, many researchers utilized Operational Research to model a wide range of disastrous situations (Jahre et al., 2007). Many governments realized the vital role of logistics in humanitarian disasters and implemented proposed mathematical models by scholars. And this implementation led to a reduction in both human and financial losses of natural disasters (Tatham \& Christopher, 2018).

Although humanitarian logistics can significantly reduce fatalities and economic losses, its effective services are very costly (Holguín-Veras et al., 2012). For instance, in Bam earthquake, the total logistical costs were over $25 \%$ of Iran's entire GDP. Distributing and managing inventory of relief commodities and medicals, supplying blood products, evacuation, removing debris, and transportation are critical activities after an earthquake (Van Wassenhove, 2006). Note that earthquake can destroy the transportation infrastructure which makes the distribution and evacuation difficult (Fereiduni \& Shahanaghi, 2017). Humanitarian logistics are complex. Several factors play important roles in this complexity. First, after earthquakes, the time window for rescue operation is short. Therefore, many studies considered time and speed as important factors throughout rescue operations and distribution relief commodities (See Ahmadi et al. (2015) and Cozzolino (2012)). The next factor that makes the humanitarian logistic complex is the dynamic behavior of demand for relief commodities. During the first hours, people in the affected area need more services. Jabbarzadeh et al. (2014) considered this dynamic behavior for blood supply chain in disasters. Third, after earthquakes occurrence, real situations involve different decision-makers in multi levels related by a preset hierarchy (Gutjahr \& Dzubur, 2016). For example, the government of the affected country may act as the leader and distribute relief commodities in the affected areas, and international and local suppliers may play as the followers and transport their relief commodities to the affected country's warehouses (Camacho-Vallejo et al., 2015). Finally, according to John and Ramesh (2016), lack of a central authority can make huge problems. Under such situations, there might be a lot of confusion and chaos in the entire planning and execution of the relief operations. In other words, during earthquake, players may change their role in the game. For example, in Bam earthquake, Iranian government played as the leader and international suppliers played as the followers, however, when the government couldn't satisfy evacuating demands appropriately international suppliers sent their manpower and facilities in the affected area that acted independently, but they were obliged to obey Iran's law. In such situations, leader and follower players change their role dynamically. It means in some time periods the affected country acts as the leader and in other periods it acts as the follower.

The complex nature of humanitarian logistics illustrates the need of an effective plan to respond to such possible crisis. Therefore, in this paper a non-linear multi-period multi-level model, which considers all above complexities, is introduced. The government of the affected country, on the one hand, seeks to minimize the amount of unsatisfied demands and the total costs, and on the other hand, international suppliers try to minimize their shipping costs. Usually, it is the responsibility of the government of the country where the disaster has occurred to control the entire relief operations, but sometimes the government of the country may be neither experienced nor might be having any expertise to handle such situations. In these situation, international suppliers act independently but are obliged to obey the law of the country. Most of time the affected country plays as the leader in the game and international suppliers act 
as follower, but sometimes based on different situations, the affected country must change its role and plays as a follower and consequently, the international suppliers act as the leader. To cope with this situation, we defined a multi-level model to consider probable changes in the leader's and the followers' roles. Based on different circumstances, the proposed model can have two or three levels. When it has two levels, it means the affected country is the leader and international suppliers are followers. However, when the affected country is not capable to handle disastrous situations the model turns into a three-level model which means international suppliers are the leader.

The remainder of this paper is organized as follows. Section 2 reviews related literature in humanitarian logistics. Section 3 explains the considered problem and provides basic assumptions. Section 4 defines parameters and variables and proposes the mathematical models. In section 5 the numerical results are presented. And finally, Section 6 offers concluding remarks, and gives some directions for future research in this manner.

\section{Literature Review}

In this section, we review studies related to humanitarian logistics and address the current gap in the literature. To do so, we divide the literature into two streams: single-level models and multi-level models. Single-level studies consider one decision-maker while multi-level models capture the interaction among multi decision-makers.

\subsection{Single-level Programming}

As discussed in Section 1, in 1980s many researchers utilized mathematical models to formulate the effective response in disasters. They mainly considered the logistics of relief commodities and services for injured people. In one of the very first studies, Knott (1987) presented a bi-objective model to optimize the transportation problem. The model aims to minimize transportation costs and maximize the amount of food delivered to the affected areas. Next, (Knott, 1988) developed a linear model to maximize the total amount of distributed food. The proposed model could maximize the objective function by optimizing the vehicle routing problem. In the twenty-first century, many studies were published in the context of humanitarian logistics. In what follows we review some of them. Many governments utilize helicopters to facilitate distribution and evacuation. Therefore, Barbarosoğlu et al. (2002) developed a routing and transportation problem for helicopters. Özdamar et al. (2004) proposed a mathematical model for planning logistics of relief commodities. They presented an algorithm to determine the origin and destination of each relief commodity. Fereiduni and Shahanaghi (2017) presented a multi-period robust optimization for distribution and evacuation in the disaster response phase. The single objective model aims to minimize the total costs of the network while it makes the most optimal decisions related to location, distribution, and evacuation. Rodríguez-Espíndola et al. (2018) introduced multi-objective programming for a disaster preparedness system using geographical information systems. The proposed model determines the optimal location of facilities, distributes relief products, selects the optimal resource allocation, and ascertains the number of required actors to perform these activities. Chapman and Mitchell, (2018) developed a mathematical model to choose a set of distribution centers among potential facilities and allocate affected people to located distribution centers.

\subsection{Multi-level Programming}

In a real situation, decision-makers interact in two or more levels because each of them can control only limited variables. These hierarchical problems do not encompass multi-objective optimization because in these kinds of problems there are more than one decision-makers. Multi-level programming, as a powerful method, helps authors to formulate this complicated situation. The decision-maker in the upper level is called the leader, and the lower levels are called the followers. At each level, constraints exist, and decision-makers will optimize their objective function by controlling a set of variables. 
After intense earthquakes, international and local suppliers offer to help the affected country by sending aid commodities and human resources. For instance, after the Bam earthquake, in December 2003, 68 international organizations helped Iran. Although multi-level programming has been applied in a wide range of applications, only a few studies have investigated multi-level programming in the context of humanitarian logistics. Most of these papers focus on unnatural disasters that are subject to human activity, such as terrorist attacks. One of the first studies in this context was conducted by Arroyo and Galiana (2005). They investigated the terrorist thread problem using bi-level programming formulation. The goal of the destructive agent is to maximize loss of load by minimizing the number of power system components that must be destroyed. On the other hand, the system operator tries to minimize the level of system load shed. Furthermore, Aksen et al. (2013) developed a bi-level programming model for the protection of critical facilities between a defender, as the leader, and a potential attacker, as the follower, by using static Stackelberg game between the leader and the follower. Facilities were considered in both protected and unprotected mode. The leader tries to minimize the sum of install costs, protection, and usage of the facility while the follower seeks to destroy unprotected facilities. Their results showed that protection budget has a substantial impact on the maintenance of critical facilities. Finally, Losada et al. (2012) presented bi-level programming for a facility location problem. In this paper, the upper-level chooses which disruption scenarios will hit the user's system, and the lower level defines an appropriate strategy for the user's system. The upper level maximizes disruption, and the lower level minimizes traveling distance.

Bi-level programming in the context of natural disasters has been studied in a few articles. The first study in this area was conducted by Barbarosoğlu et al. (2002) with focusing on the preparation stage. They investigated the helicopter relief mission using bi-level programming. The upper level makes decisions about pilot composition and tour number for each helicopter. And the lower level involves decisions about rescue schedules, vehicle routing, and transshipment. Moreover, they designed a coordination procedure to deal with the hierarchical decomposition. Feng and Wen (2005) proposed a bi-level model considering roads traffic after severe earthquakes to optimize transportation in evacuation and rescue in this situation. In the upper level, the leader maximizes the number of vehicles entering the affected areas. On the other hand, the lower level seeks to minimize travel time through the network. To optimize decisions related to aid distribution after the earthquake, a bi-level model was proposed by Camacho-Vallejo et al. (2015). In the upper level, the affected county tries to minimize total response time. In the lower level, international organization and foreign countries, as suppliers, seek to minimize their transportation cost. Angelo and Barbosa (2015) presented a bi-level transportation routing problem. In the upper level, the total travel cost of serving all customers is minimized, and at the lower level, the minimum cost of transportation and allocation of resources are determined. Finally, Gutjahr and Dzubur (2016) developed a bi-level model to determine the location of relief distribution centers in a post-disaster situation. In the upper level, the organization which provides supply and establishes distribution centers tries to minimize total opening cost and total unsatisfied demand. In the lower level, the beneficiaries determine which distribution centers should provide supplements.

According to the literature, there is an absolute scientific gap in multi-level models, especially for natural disasters. Multi-level programming is a powerful method to take numerous decision-makers with different goals into account. However, considering only multi-level programming that the leader and the follower are predetermined is not realistic. According to real-world examples such as the Bam earthquake, after earthquakes, the government may turn into a follower. Moreover, international suppliers may turn into the leader (only for limited services such as evacuation). For instance, if the government of the affected country is unable to meet the demand effectively, international suppliers send their human resources to the affected country and do not let the government disrupts their policy. This conveys that the position of government as the leader is not stable, and it may turn into the follower.

In this paper, a dynamic multi-level model is proposed. When the government can handle evacuating demand properly, the government is the leader and seeks to minimize the number of unsatisfied demands 
and the total costs. While international suppliers, in the lower level, try to reduce their transportation costs. However, when the government doesn't have any expertise to handle disastrous situations, international suppliers send their aid and human resources to the affected areas and evacuate injured people. In this situation, the bi-level model turns into a tri-level model which international suppliers in evacuating operations act as the leader. Note that they are still followers (the third level) in other services such as sending relief commodities.

\section{Problem Statement}

When an earthquake occurs, international suppliers help the affected country by sending relief commodities such as water, food, medicine, and shelter. At the upper level, the affected country is responsible for transporting aids from warehouses to affected sites and evacuating injuries from affected areas and transporting them to medical centers. At the lower level, international suppliers deliver relief commodities to pre-defined warehouses and try to minimize their transportation cost. When the government of the affected country cannot evacuate injured people effectively, international suppliers help the government by sending human resources. Therefore, for evacuation services, the international suppliers become the leader (while they are still followers for the rest of operations). To challenge this problem, we defined an auxiliary level, which turns the bi-level model into the tri-level model. In other word, the evacuating part of international suppliers acts as the leader for the government of the affected area. Figure 1 shows a schematic structure of this problem. We propose a dynamic multi-level multi-commodity and multi-period model to optimize decisions related to aid distribution and evacuation after an earthquake. At the auxiliary level, which will be activated under special conditions, the evacuating part of the international suppliers acts as the leader to minimize the shipping costs. At the second level, the government of the affected country decides how to distribute aids from warehouses to demand sites and evacuate injuries to minimize unsatisfied demands and total costs. At the third level, international suppliers send their aid products to warehouses and try to reduce their shipping costs. In what follows the main assumptions of the proposed model are presented; (1) if the government of the affected area cannot handle evacuating operation properly, the auxiliary level will be activated, and the proposed model turns into a tri-level model. (2) international suppliers have limited capacities to send relief commodities. (3) all demand points must be satisfied at least partially, (4) demands for evacuation must be satisfied in specific times. (4) international suppliers send their relief commodities to pre-positing warehouses. (5) evacuation services offered by international suppliers are independent of their other services. (6) there are different types of rescue vehicles for evacuation with known capacities. (7) the existence of a coordinator agency between affected country and international suppliers to avoid sending unnecessary relief commodities (Camacho-Vallejo et al. 2015).

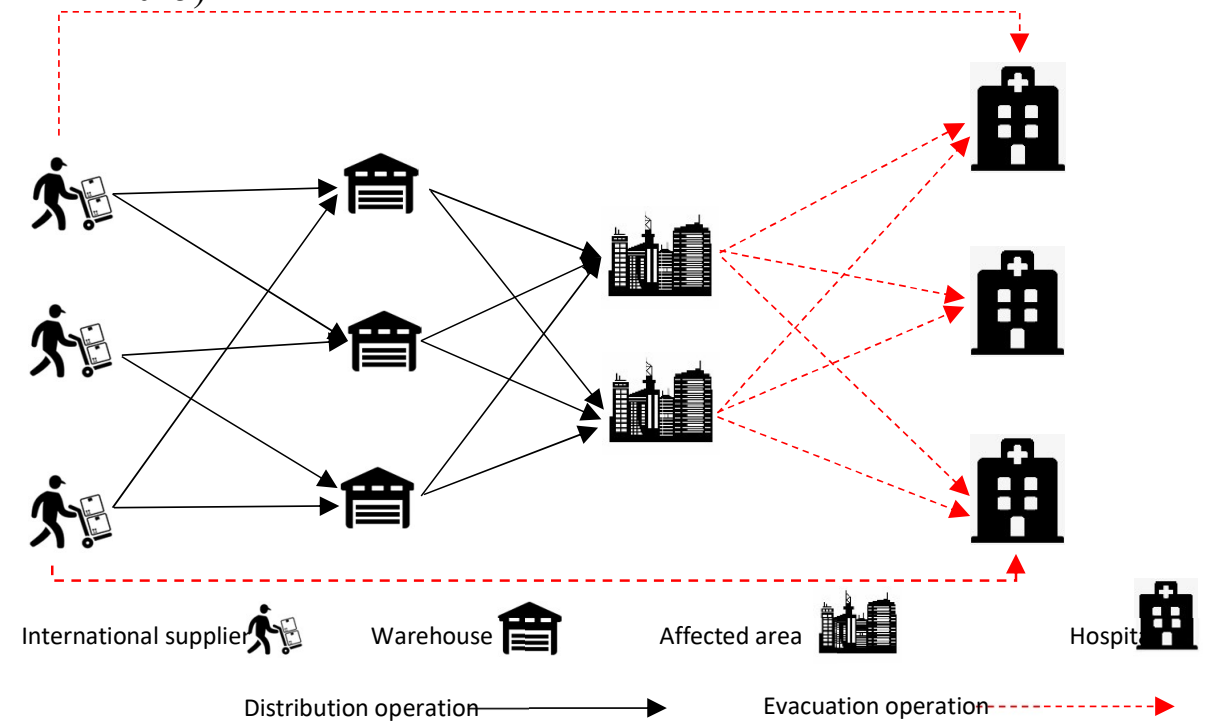

Fig. 1. Schematic structure of the problem 


\section{Model Formulation}

According to Section 3, the proposed multi-level model is developed. The utilized indices, parameters, and decision variables are presented in Table 1, Table 2, and Table 3, respectively.

\section{Table 1}

Set of indices

\begin{tabular}{ll}
\hline Indices & \\
\hline$i \in\{1,2, \ldots, I\}$ & Set of affected areas \\
$e \in\{1,2, \ldots, E\}$ & Set of international suppliers \\
$j \in\{1,2, \ldots, J\}$ & Set of pre-positing warehouses \\
$q \in\{1,2, \ldots, Q\}$ & Set of relief commodities \\
$k \in\{1,2, \ldots, K\}$ & Set of medical centers \\
$l \in\{1,2, \ldots, L\}$ & Set of rescue vehicles \\
$t \in\{1,2, \ldots, T\}$ & Set of time periods \\
\hline
\end{tabular}

\section{Table 2}

Definition of Parameters

\begin{tabular}{ll}
\hline Parameters & \\
\hline$O_{l}$ & Unit of operational costs of rescue vehicle $l$ in warehouses. \\
$O_{q}^{\prime}$ & Unit of operational costs of commodity $q$ in warehouses. \\
\hline$W_{l}$ & Unit of transportation costs of rescue vehicle $l$. \\
\hline$W_{q}^{\prime}$ & Unit of transportation costs of commodity $q$. \\
\hline$W_{q}^{\prime \prime}$ & Unit of transportation costs of commodity $q$ for international suppliers. \\
\hline$W_{l}^{\prime \prime \prime}$ & Unit of transportation costs of rescue vehicle $l$ for international suppliers. \\
\hline$r$ & Coverage radius of warehouses. \\
\hline$d_{i j}$ & Distance between affected area $i$ and warehouse $j$. \\
\hline$d_{i k}^{\prime}$ & Distance between affected area $i$ and medical center $k$. \\
\hline$d_{e j}^{\prime \prime}$ & Distance between international supplier $e$ and warehouse $j$. \\
\hline$d_{e i}^{\prime \prime}$ & Distance between international supplier $e$ and affected area $i$. \\
\hline$T_{i}^{t}$ & Maximum time that rescue operations should be done at affected area $i$ in period $t$. \\
\hline$V_{l}$ & Average velocity of rescue vehicle $l$. \\
\hline$g_{l}$ & Capacity of rescue vehicle $l$. \\
\hline$M$ & A very large number \\
\hline$\alpha$ & Maximum acceptable amount of unsatisfied demand for evacuating demand \\
\hline$D_{i}^{\prime}$ & Number of injured people at affected area $i$ in period $t$. \\
\hline$D_{i q}^{\prime l}$ & Demand of commodity q at affected area $i$ in period $t$. \\
\hline$b_{e q}$ & Available quantity of relief commodity $q$ in international supplier $e$. \\
\hline$b_{e l}^{\prime}$ & Available number of rescue vehicle $l$ in international supplier $e$. \\
\hline$\lambda_{j l}$ & Available rescue vehicle $l$ at warehouse $j$. \\
\hline & \\
\hline
\end{tabular}


Table 3

Definition of decision variables

\begin{tabular}{l|l}
\hline Decision variables & \\
\hline$\eta_{j l i k}^{t}$ & $\begin{array}{l}\text { If rescue vehicle } l \text { from warehouse } j \text { is assigned to affected area } i \text { and hospital } k \\
\text { in period } t \text { equals to } 1 \text {, otherwise } 0 .\end{array}$ \\
\hline$Y_{j q i}^{t}$ & $\begin{array}{l}\text { The proportion of satisfied demand of relief commodity } q \text { that is satisfied by } \\
\text { warehouse } j \text { in period } t .\end{array}$ \\
$\delta_{i}^{t}$ & Uncovered injured people in area $i$ in period $t$. \\
$\gamma_{e q j}^{t}$ & $\begin{array}{l}\text { Amount of shipments of the relief commodity } q \text { sent by international supplier } e \\
\text { to warehouse } j \text { in period } t .\end{array}$ \\
$\gamma_{e l i k}^{\prime t}$ & $\begin{array}{l}\text { If rescue vehicle } l \text { from international supplier } e \text { is assigned to affected area } i \text { and } \\
\text { medical center } k \text { in period } t \text { equals to } 1 \text {, otherwise } 0 .\end{array}$ \\
$X$ & $\begin{array}{l}\text { A binary variable which equals to } 1 \text { when the affected country cannot satisfy } \\
\text { evacuating demands properly, otherwise } 0 .\end{array}$ \\
\hline
\end{tabular}

To simplify the proposed model, we summarized some costs components as follows:

$$
\begin{aligned}
O C & =\sum_{j \in J} \sum_{k \in K} \sum_{l \in L} \sum_{i \in I} \sum_{t \in T} \beta_{t} \eta_{j l i k}^{t}+\sum_{q \in Q} \sum_{j \in J} \sum_{i \in I} \sum_{t \in T} \beta_{q}^{t} Y_{j q i}^{t} D_{i q}^{\prime t} \\
T C & =\sum_{j \in J} \sum_{k \in K} \sum_{l \in L} \sum_{i \in I} \sum_{t \in T}\left(d_{i j}+d_{i k}\right) W_{l} \eta_{j l i k}^{t}+\sum_{q \in Q} \sum_{j \in J} \sum_{i \in I} \sum_{t \in T} d_{i j} W_{q}^{\prime} Y_{j q i}^{t} D_{i q}^{\prime t}
\end{aligned}
$$

Equation (1) shows operations costs of the government of the affected area which involve two parts: the first part consists operational costs of evacuating operations and the second parts consists operational costs of distributing operations. Equation (2) defines transportation costs of the government of the affected area which involve transportation costs of evacuating and distributing operations costs.

Now we formulate the multi-level model based on details:

First, we discuss the Auxiliary Level. This level is activated when the government of the affected area cannot handle the evacuation operation properly $(\$ X=1 \$)$. Therefore, the Auxiliary Level belongs to evacuation part of international suppliers.

$$
\begin{aligned}
& \min \sum_{t \in T}\left[\left(\sum_{l \in L} \sum_{i \in I} \sum_{k \in K} \sum_{e \in E}\left(d_{e i}^{\prime \prime \prime}+d_{i k}\right) \gamma_{e l i k}^{\prime t} W_{l}^{\prime \prime \prime}\right) X\right] \\
& \sum_{k \in K} \sum_{t^{\prime} \in T} \sum_{i \in I} \gamma_{e l i k}^{\prime t} \leq b_{e l}^{\prime} \quad \forall e \in E, \forall l \in L \\
& \gamma_{e l i k}^{\prime t} \geq 0 \quad \forall e \in E, \forall l \in L, \forall i \in I, \forall t \in T, \forall k \in K \\
& X \in\{0,1\}
\end{aligned}
$$

Eq. (3) determines the shipping costs of international suppliers for evacuation operation, which will be activated if the government of affected area cannot handle the demand for evacuation. Inequality (4) shows available rescue vehicles for each international supplier. Inequalities (5) and (6) define the decision variables in the Auxiliary Level. Note that if the government of the affected area properly handles the demand for evacuation ( $X=0$ ), then the Auxiliary Level does not exist. Next, the objective functions and constraints of the Second Level are described. The Second Level belongs to the government of the affected area. Therefore, if the government properly handles the demand for evacuation $(X=0)$, the Auxiliary Level does not exist, and the government is the leader. Otherwise $(X=1)$, the government acts like a follower. Eq. (7) shows the first objective function of the government of the affected area 
which aims to minimize the summation of unmet demands for relief commodities and evacuation operation. The second objective function of the government is shown in Eq. (8) which minimizes the total costs including operation cost and transportation cost.

$$
\begin{aligned}
& \min \sum_{i \in I} \sum_{q \in Q} \sum_{t \in T} \sum_{j \in J}\left(1-Y_{j q i}^{t}\right) \cdot D_{q i}^{\prime t}+\sum_{t \in T} \sum_{i \in I} \delta_{i}^{t} \\
& \min O C+T C
\end{aligned}
$$

Inequality (9) guarantees all demand points for all type of relief commodities should be satisfied (at least partially). Inequality (10) shows available rescue vehicles in warehouses based on the capacity of warehouses. Next, Inequality (11) ensures that the demands for evacuation should be responded in specific time window. Inequality (12) demonstrates radius coverage for evacuation operations.

$$
\begin{aligned}
& \sum_{j \in J} Y_{j q i}^{t} \succ 0 \forall q \in Q, \forall i \in I, \forall t \in T \\
& \sum_{t \in T} \sum_{i \in I} \sum_{k \in K} \eta_{j l i k}^{t} \leq \lambda_{j l} \quad \forall j \in J, \forall l \in L \\
& d_{i j} \eta_{j l i k}^{t} \leq T_{i}^{t} V_{l} \quad \forall j \in J, \forall l \in L, \forall i \in I, \forall t \in T \\
& d_{i j} \eta_{j l i k}^{t} \leq r \quad \forall k \in K, \forall j \in J, \forall l \in L, \forall i \in I, \forall t \in T
\end{aligned}
$$

Eq. (13) guarantees that all demands for evacuation should be satisfied (at least partially). Inequality (14) relates the Auxiliary Level to the Second Level and shows that if the government of the affected area cannot meet evacuating demand properly, the auxiliary level will be activated. Eq. (15) demonstrates how demands for evacuation should be satisfied. Based on different situations, the government and international suppliers can satisfy these demands (at least partially). Furthermore, Eq. (15) determines the amount of unsatisfied demand. Inequality (15) shows that the maximum distributed relief commodities in each affected area is less than that affected area's demand. Finally, Inequality (17) defines the decision variable at the second level.

$$
\begin{aligned}
& \sum_{j \in J} \sum_{l \in L} \sum_{k \in K} \eta_{j l i k}^{t} \geq 1 \quad \forall i \in I, \forall t \in T \\
& \left(\sum_{i} \delta_{i}^{t s}-\alpha\right) \leq M . X \quad \forall t \in T \\
& \sum_{j \in J} \sum_{k \in K} \sum_{l \in L} \eta_{j l i k}^{t} g_{l}+\delta_{i}^{t}+\left(\sum_{l \in L} \sum_{k \in K} \sum_{e \in E} \gamma_{e l i k}^{t} g_{l}\right) X=D_{i}^{t} \quad \forall i \in I, \forall t \in T \\
& \sum_{j \in J} Y_{j q i}^{t} \cdot D_{q i}^{\prime t} \leq D_{q i}^{\prime t} \quad \forall q \in Q, \forall t \in T \\
& \eta_{j l i k}^{t} \in\{0,1\}, Y_{j q i}^{t} \in[0,1], \delta_{i}^{t} \geq 0 \quad \forall l \in L, \forall k \in K, \forall j \in J, \forall i \in I, \forall j \in J, \forall t \in T
\end{aligned}
$$

Now the Third Level is formulated and described. Note that the Third Level belongs to distribution part of international suppliers. This part is the follower of the government no matter what happens. Eq. (18) is the objective function of international suppliers, which tries to minimize transportation costs of shipping relief commodities to the affected country.

$$
\min \sum_{q \in Q} \sum_{j \in J} \sum_{t \in T} \sum_{e \in E} W_{q}^{\prime \prime t} \cdot d_{e j}^{\prime \prime} \cdot \gamma_{e q j}^{t}
$$


Eq. (19) explains that all distributed relief commodities in the affected areas are equal to received aids from international suppliers. Eq. (20) shows available relief commodities for each international supplier. Finally, Inequality (21) defines decision variables in the third level.

$$
\begin{aligned}
& \sum_{e \in E} \gamma_{e q j}^{t}=\sum_{j \in J} Y_{j q i}^{t} D_{q i}^{t} \forall q \in Q, \forall j \in J, \forall t \in T \\
& \sum_{t \in T} \sum_{j \in J} \gamma_{e q j}^{t} \leq b_{e q} \forall e \in E, \forall q \in Q \\
& \gamma_{e q j}^{t} \geq 0 \quad \forall e \in E, \forall q \in Q, \forall j \in J, \forall t \in T
\end{aligned}
$$

Since the proposed model is non-linear, it is reformulated to a linear model before solving. The linearization technique is presented as follows.

\subsection{Reformulated Linear Model}

If $x \geq 0$ and $y \in\{0,1\}$, the non-linear term of $x . y$ can be replaced by a new variable $z$. As a result, three constraint will be added to the model as follows:

$$
\begin{aligned}
& z \leq x \\
& \mathrm{z} \leq M \cdot y \\
& x-M \times[1-y] \leq z
\end{aligned}
$$

Here we define two variables in Eq. (25) and Eq. (26), which help to understand the linearization process easier.

$$
\begin{aligned}
& \phi^{t}=\left(\sum_{l \in L} \sum_{i \in I} \sum_{k \in K} \sum_{e \in E} W_{l}^{\prime \prime \prime}\left(d_{e i}^{\prime \prime \prime}+d_{i k}\right) \gamma_{e l i k}^{\prime t}\right) X \quad \forall t \in T \\
& \theta_{i}^{t}=\left(\sum_{l \in L} \sum_{k \in K} \sum_{e \in E} \gamma_{e l i k}^{t} g_{l}\right) X \quad \forall i \in I, t \in T
\end{aligned}
$$

According to Inequalities (22), (23), and (24), and new defined variables in Eq. (25) and Eq. (26), we present the linear form of proposed non-linear multi-level model below. Note that the sets, parameters and other variables in linear model are as the same as non-linear multi-level model. The linear form of the Auxiliary Level is as what follows. Eq. (27) shows the linear form of the Auxiliary Level's objective function in Equation (3). Inequality (28) is as the same as Inequality (4). Inequalities (29), (30), and (31) ensure that the model is linear. Finally, Eq. (32) defines decision variables in the Auxiliary Level.

$$
\begin{aligned}
& \min \sum_{t \in T} \phi^{t} \\
& \sum_{k \in K} \sum_{t^{\prime} \in T} \sum_{i \in I} \gamma_{\text {elik }}^{\prime t} \leq b_{e l}^{\prime} \quad \forall e \in E, \forall l \in L \\
& \phi^{t} \leq \sum_{l \in L} \sum_{i \in I} \sum_{k \in K} \sum_{e \in E} W_{l}^{\prime \prime \prime}\left(d_{e i}^{\prime \prime \prime}+d_{i k}\right) \gamma_{e l i k}^{\prime t} \quad \forall t \in T \\
& \phi^{t} \leq M X \quad \forall t \in T \\
& \left(\sum_{l \in L} \sum_{i \in I} \sum_{k \in K} \sum_{e \in E} W_{l}^{\prime \prime \prime}\left(d_{e i}^{\prime \prime \prime}+d_{i k}^{\prime}\right) \gamma_{\text {elik }}^{\prime t}\right)-M[1-X] \leq \phi^{t} \quad \forall t \in T
\end{aligned}
$$




$$
\gamma_{e q j}^{t} \geq 0, \phi^{t} \geq 0, X \in\{0,1\} \quad \forall e \in E, \forall q \in Q, \forall j \in J, \forall t \in T
$$

The linear form of the Second Level is provided below. Eq. (33) and Eq. (34) are the Second Level's objective functions as described in Eq. (7) and Eq. (8). Moreover, Inequality (35) to Inequality (40) are the same as constraint (9) to (14) in the non-linear model.

$$
\begin{aligned}
& \min \sum_{i \in I} \sum_{q \in Q} \sum_{t \in T} \sum_{j \in J}\left(1-Y_{j q i}^{t}\right) \cdot D_{q i}^{t}+\sum_{t \in T} \sum_{i \in I} \delta_{i}^{t} \\
& \min O C+T C \\
& \sum_{j \in J} Y_{j q i}^{t} \succ 0 \quad \forall q \in Q, \forall i \in I, \forall t \in T \\
& \sum_{t \in T} \sum_{i \in I} \sum_{k \in K} \eta_{j l i k}^{t} \leq \lambda_{j l} \quad \forall j \in J, \forall l \in L \\
& d_{i j} \eta_{j l i k}^{t} \leq T_{i}^{t} V_{l} \quad \forall j \in J, \forall l \in L, \forall i \in I, \forall t \in T \\
& d_{i j} \eta_{j l i k}^{t} \leq r \quad \forall k \in K, \forall j \in J, \forall l \in L, \forall i \in I, \forall t \in T \\
& \sum_{j \in J} \sum_{l \in L} \sum_{k \in K} \eta_{j l i k}^{t} \geq 1 \quad \forall i \in I, \forall t \in T \\
& \left(\sum_{i} \delta_{i}^{t s}-\alpha\right) \leq M X \quad \forall t \in T
\end{aligned}
$$

Inequality (41) to Inequality (44) are the linear form of Inequality (15). Furthermore, Eq. (45) has the same explanation as Eq. (16). Finally, Eq. (46) defines the decision variables in the linear Second Level.

$$
\begin{aligned}
& \sum_{j \in J} \sum_{k \in K} \sum_{l \in L} \eta_{j l i k}^{t} g_{l}+\delta_{i}^{t}+\theta_{i}^{t}=D_{i}^{t} \quad \forall i \in I, \forall t \in T \\
& \theta_{i}^{t} \leq \sum_{l \in L} \sum_{k \in K} \sum_{e \in E} \gamma_{e l i k}^{t} g_{l} \quad \forall t \in T, \forall i \in I \\
& \theta_{i}^{t} \leq M X \quad \forall t \in T, \forall i \in I \\
& \sum_{l \in L} \sum_{k \in K} \sum_{e \in E} \gamma_{e l i k}^{t} g_{l}-M[1-X] \leq \theta_{i}^{t} \forall t \in T, \forall i \in I \\
& \sum_{j \in J} Y_{j q i}^{t} \cdot D_{q i}^{\prime t} \leq D_{q i}^{\prime t} \quad \forall q \in Q, \forall t \in T \\
& \eta_{j l i k}^{t} \in\{0,1\}, \delta_{i}^{t} \geq 0, Y_{j q i}^{t} \in[0,1], \theta_{i}^{t} \geq 0 \quad \forall l \in L, \forall k \in K, \forall j \in J, \forall i \in I, \forall j \in J, \forall t \in T
\end{aligned}
$$

Finally, we present the linear form of the Third Level which is the same as the Third Level in the nonlinear model. Therefore, Eq. (47) to Eq. (50) have the same explanation as Eq. (18) to Eq. (21).

$$
\begin{aligned}
& \min \sum_{q \in Q} \sum_{j \in J} \sum_{t \in T} \sum_{e \in E} W_{q}^{\prime \prime t} \cdot d_{e j}^{\prime \prime} \cdot \gamma_{e q j}^{t} \\
& \sum_{e \in E} \gamma_{e q j}^{t}=\sum_{j \in J} Y_{j q i}^{t} D_{q i}^{t} \quad \forall q \in Q, \forall j \in J, \forall t \in T \\
& \sum_{t \in T} \sum_{j \in J} \gamma_{e q j}^{t} \leq b_{e q} \quad \forall e \in E, \forall q \in Q \\
& \gamma_{e q j}^{t} \geq 0 \quad \forall e \in E, \forall q \in Q, \forall j \in J, \forall t \in T
\end{aligned}
$$




\section{Results}

To illustrate and apply our proposed model, we consider the probable earthquake in Tehran region one. The north Tehran fault is one of the most active faults in Tehran, which can lead to an earthquake in this city. In this paper, we consider the effect of this fault on Tehran region one as our case study. After the occurrence of an earthquake, groups of foreign countries will help the affected zone by sending necessary commodities. Suppliers choose the cheapest transportation plan to ship commodities to located warehouses, and the affected country will distribute commodities from warehouses to demanded nodes. The suppliers try to minimize their transportation costs while the government of Iran would have like to minimize unsatisfied demands and total costs. The government also evacuate injuries from the affected areas and transport them to medical centers. As we said before, if the government cannot satisfy evacuating demand properly, international suppliers help the country as an independent party. Different kinds of rescue vehicles will do this operation. Trucks, ambulances, and helicopters are considered as rescue vehicles. We assume ten countries will help Tehran after the earthquake, including Iraq, Turkey, Azerbaijan, Syria, UAE, Qatar, Germany, Turkmenistan, Kuwait, and Afghanistan. The relief commodities are in three groups, food and water, and medicine. Four located warehouses and three medical centers are considered in this model. Fig. 2 shows the location of these warehouses and medical centers in Tehran region one. We also assume the Red Cross and Helal-e-Ahmar agency coordinating Tehran with foreign countries to avoid sending unnecessary commodities to warehouses.

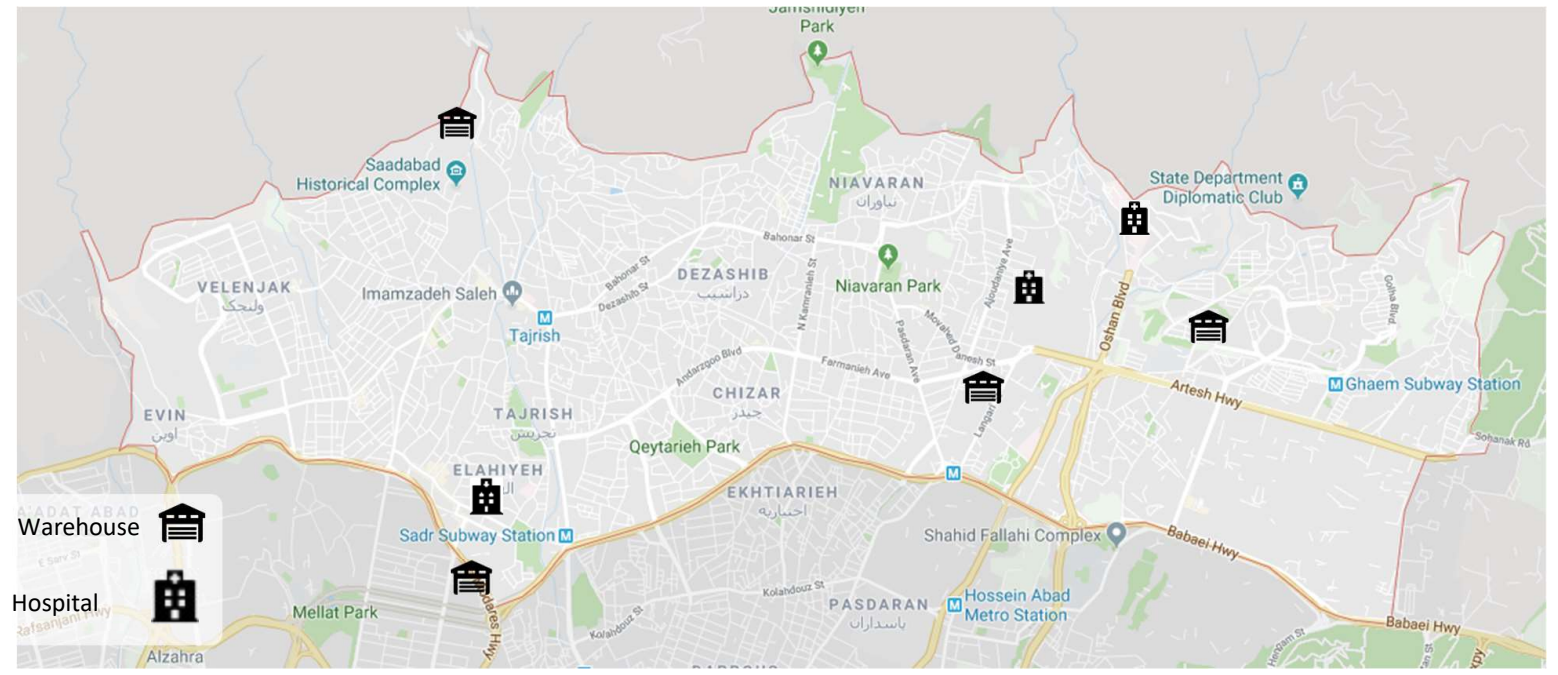

Fig. 2. The location of these warehouses and medical centers in Tehran region 1.

Region one consists of ten areas. We assume the center of each area as the demand nodes. The utilized parameters are shown in Table 2 to Table 6. Table 2 displays the latitude and longitude of the affected areas, medical centers, warehouses, and international suppliers. Based on Eq. (51) and Table 4, distances between nodes can be calculated.

$$
d_{i j}=6371.1 \times \arccos \left[\sin \left(L A T_{i}\right) \times \sin \left(L A T_{j}\right)+\cos \left(L A T_{i}\right) \times \cos \left(L A T_{j}\right) \times \cos \left(L O N_{j}-L O N_{i}\right)\right]
$$

Table 5 shows the demands for relief commodities of ten areas in Tehran region one for six periods. Table 6 displays demands for evacuating operation of these areas for six times periods. Table 7 demonstrates rescue vehicles characteristics containing their capacity to carry injuries, the available number of them in warehouses and international suppliers, and their average velocity. Table 8 shows acceptable times to satisfy evacuating demands of demand points. We assume that these times are consistent in all periods. Table 9 shows the international suppliers' capacities for relief commodities. Finally, Table 10 contains the unit of transportation and operation costs of the government and international suppliers for distribution and evacuation. In this section, we propose the numerical results conducted for the proposed 
case study. A comparison between four points of view is proposed to show the benefits of multi-level modeling. First, the model is investigated from the standpoint of the independent part of international suppliers which help Iran under situations, the leader of the multi-level model. Second, the perspective of Iran government, third the standpoint of dependent part of international suppliers and finally, the leader-follower model in a multi-level structure are investigated. To solve the multi-level model, we used the Fuzzy Goal Programming (FGP) approach and reduced the multi-level model to an equivalent singlelevel model.

Table 4

The latitude and longitude of the affected areas, medical centers, warehouses and international suppliers

\begin{tabular}{|c|c|c|}
\hline Points & latitude & longitude \\
\hline Affected area 1 & 35.810363 & 51.422087 \\
\hline Affected area 2 & 35.794213 & 51.433588 \\
\hline Affected area 3 & 35.815931 & 51.442772 \\
\hline Affected area 4 & 35.797554 & 51.451183 \\
\hline Affected area 5 & 35.804725 & 51.461569 \\
\hline Affected area 6 & 35.815444 & 51.475559 \\
\hline Affected area 7 & 35.809736 & 51.483198 \\
\hline Affected area 8 & 35.799782 & 51.483971 \\
\hline Affected area 9 & 35.805699 & 51.509806 \\
\hline Affected area 10 & 35.791915 & 51.504484 \\
\hline Hospital 1 & 35.789043 & 51.431951 \\
\hline Hospital 2 & 35.793012 & 51.487226 \\
\hline Hospital 3 & 35.816349 & 51.494700 \\
\hline Warehouse 1 & 35.780308 & 51.429619 \\
\hline Warehouse 2 & 35.821693 & 51.429705 \\
\hline Warehouse 3 & 35.798966 & 51.491074 \\
\hline Warehouse 4 & 35.802693 & 51.513316 \\
\hline Turkey & 39.907253 & 32.835508 \\
\hline Azerbaijan & 38.755752 & 48.838380 \\
\hline Iraq & 33.335705 & 44.347654 \\
\hline Syria & 36.455217 & 40.790400 \\
\hline UAE & 24.324056 & 54.815086 \\
\hline Germany & 49.410104 & 11.087382 \\
\hline Turkmenistan & 37.951214 & 58.325804 \\
\hline Qatar & 25.286020 & 51.597424 \\
\hline Kuwait & 29.390573 & 47.982057 \\
\hline Afghanistan & 34.554518 & 69.115289 \\
\hline
\end{tabular}

Table 5

Demands for relief commodities of 10 areas in Tehran region 1 for 6 time periods

\begin{tabular}{|c|c|c|c|c|c|c|c|c|}
\hline Area & Period & Food & Water & Medicine & Period & Food & Water & Medicine \\
\hline 1 & \multirow{10}{*}{ 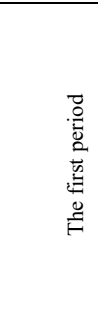 } & 17038 & 17038 & 17038 & \multirow{10}{*}{ 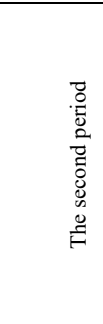 } & 16527 & 16527 & 16527 \\
\hline 2 & & 28410 & 28410 & 28410 & & 27557 & 27557 & 27557 \\
\hline 3 & & 27570 & 27570 & 27570 & & 26743 & 26743 & 26743 \\
\hline 4 & & 19400 & 19400 & 19400 & & 18818 & 18818 & 18818 \\
\hline 5 & & 16266 & 16266 & 16266 & & 15778 & 15778 & 15778 \\
\hline 6 & & 8207 & 8207 & 8207 & & 7960 & 7960 & 7960 \\
\hline 7 & & 25887 & 25887 & 25887 & & 25110 & 25110 & 25110 \\
\hline 8 & & 12223 & 12223 & 12223 & & 11857 & 11857 & 11857 \\
\hline 9 & & 9599 & 9599 & 9599 & & 9311 & 9311 & 9311 \\
\hline 10 & & 1582 & 1582 & 1582 & & 1535 & 1535 & 1535 \\
\hline 1 & \multirow{10}{*}{ 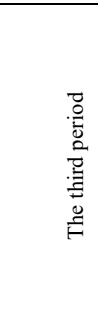 } & 13971 & 13971 & 13971 & \multirow{10}{*}{ 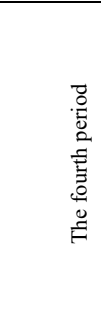 } & 10563 & 10563 & 10563 \\
\hline 2 & & 23296 & 23296 & 23296 & & 17614 & 17614 & 17614 \\
\hline 3 & & 22608 & 22608 & 22608 & & 17093 & 17093 & 17093 \\
\hline 4 & & 15908 & 15908 & 15908 & & 12028 & 12028 & 12028 \\
\hline 5 & & 13338 & 13338 & 13338 & & 10085 & 10085 & 10085 \\
\hline 6 & & 6729 & 6729 & 6729 & & 5088 & 5088 & 5088 \\
\hline 7 & & 21227 & 21227 & 21227 & & 16049 & 16049 & 16049 \\
\hline 8 & & 10023 & 10023 & 10023 & & 7578 & 7578 & 7578 \\
\hline 9 & & 7871 & 7871 & 7871 & & 5951 & 5951 & 5951 \\
\hline 10 & & 1297 & 1297 & 1297 & & 981 & 981 & 981 \\
\hline 1 & \multirow{10}{*}{ 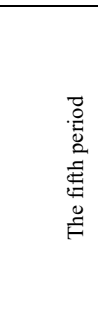 } & 6645 & 6645 & 6645 & \multirow{10}{*}{ 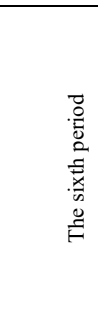 } & 2555 & 2555 & 2555 \\
\hline 2 & & 11079 & 11079 & 11079 & & 4261 & 4261 & 4261 \\
\hline 3 & & 10752 & 10752 & 10752 & & 4135 & 4135 & 4135 \\
\hline 4 & & 7566 & 7566 & 7566 & & 2910 & 2910 & 2910 \\
\hline 5 & & 6343 & 6343 & 6343 & & 2439 & 2439 & 2439 \\
\hline 6 & & 3200 & 3200 & 3200 & & 1231 & 1231 & 1231 \\
\hline 7 & & 10095 & 10095 & 10095 & & 3883 & 3883 & 3883 \\
\hline 8 & & 4767 & 4767 & 4767 & & 1833 & 1833 & 1833 \\
\hline 9 & & 3743 & 3743 & 3743 & & 1439 & 1439 & 1439 \\
\hline 10 & & 617 & 617 & 617 & & 237 & 237 & 237 \\
\hline
\end{tabular}


Table 6

Demands for evacuating operations of 10 areas in Tehran region 1 for 6 time periods.

\begin{tabular}{|c|c|c|c|c|c|c|}
\hline Area & Period & Demand & Period & Demand & Period & Demand \\
\hline 1 & \multirow{10}{*}{ 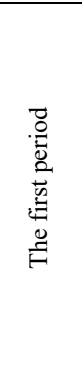 } & 64 & \multirow{10}{*}{ 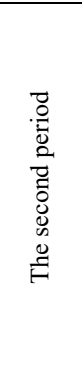 } & 60 & \multirow{10}{*}{ 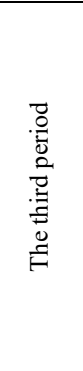 } & 45 \\
\hline 2 & & 67 & & 59 & & 45 \\
\hline 3 & & 70 & & 65 & & 53 \\
\hline 4 & & 59 & & 50 & & 46 \\
\hline 5 & & 31 & & 28 & & 22 \\
\hline 6 & & 60 & & 58 & & 39 \\
\hline 7 & & 45 & & 39 & & 32 \\
\hline 8 & & 35 & & 27 & & 24 \\
\hline 9 & & 32 & & 30 & & 28 \\
\hline 10 & & 27 & & 21 & & 15 \\
\hline 1 & \multirow{10}{*}{ 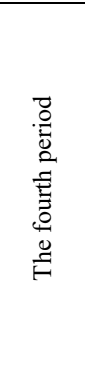 } & 39 & \multirow{10}{*}{ 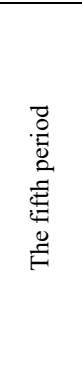 } & 33 & \multirow{10}{*}{ 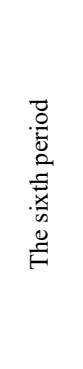 } & 25 \\
\hline 2 & & 41 & & 39 & & 20 \\
\hline 3 & & 49 & & 41 & & 31 \\
\hline 4 & & 12 & & 9 & & 6 \\
\hline 5 & & 24 & & 15 & & 10 \\
\hline 6 & & 30 & & 22 & & 13 \\
\hline 7 & & 19 & & 12 & & 8 \\
\hline 8 & & 21 & & 17 & & 12 \\
\hline 9 & & 21 & & 13 & & 9 \\
\hline 10 & & 10 & & 8 & & 5 \\
\hline
\end{tabular}

Table 7

Rescue vehicles information

\begin{tabular}{ccccc}
\hline Rescue vehicle & Average velocity $(\mathrm{km} / \mathrm{h})$ & Capacity & $\begin{array}{c}\text { available in each ware- } \\
\text { house }\end{array}$ & $\begin{array}{c}\text { available in each sup- } \\
\text { plier }\end{array}$ \\
\hline 1 & 60 & 8 & 4 & 2 \\
2 & 70 & 3 & 6 & 1 \\
3 & 180 & 5 & 2 & 0 \\
\hline
\end{tabular}

Table 8

Acceptable times to satisfy evacuating demands of demand points

\begin{tabular}{lllllllllll} 
& 1 & 2 & 3 & 4 & 5 & 6 & 7 & 8 & 9 & 10 \\
\hline Time (hour) & 0.5 & 1 & 0.7 & 0.6 & 0.5 & 1 & 0.4 & 0.7 & 0.5 & 1 \\
\hline
\end{tabular}

Table 9

International suppliers' capacities for relief commodities

\begin{tabular}{lccc}
\hline Suppliers & \multicolumn{3}{c}{ Relief commodity } \\
\cline { 2 - 4 } & Water & Food & Medicine \\
\hline Turkey & 94500 & 102000 & 36000 \\
Azerbaijan & 57500 & 84500 & 110000 \\
Iraq & 74400 & 24000 & 44000 \\
Syria & 82300 & 83900 & 62000 \\
UAE & 37700 & 34500 & 83000 \\
Germany & 56200 & 73800 & 40000 \\
Turkmenistan & 72300 & 39800 & 89000 \\
Qatar & 52900 & 53200 & 30000 \\
Kuwait & 42400 & 73100 & 63000 \\
Afghanistan & 83100 & 84300 & 92000 \\
\hline
\end{tabular}

Table 10

Unit of transportation and operation costs of the government and international suppliers for distribution and evacuation

\begin{tabular}{|c|c|c|c|c|c|c|c|c|}
\hline & \multicolumn{2}{|c|}{ Water, food, medicine } & \multicolumn{2}{|c|}{ vehicle 1} & \multicolumn{2}{|c|}{ vehicle 2} & \multicolumn{2}{|c|}{ vehicle 3} \\
\hline & Gov. & Sup. & Gov. & Sup. & Gov. & Sup. & Gov. & Sup. \\
\hline Operational cost & 0.2 & - & 170 & 250 & 100 & 150 & 700 & - \\
\hline Transportation cost & 0.04 & 0.0002 & 12 & - & 7 & - & 20 & - \\
\hline
\end{tabular}


According to (Jabbarzadeh et al., 2014), in the first periods, after earthquake occurrence demands for relief commodities and other emergency services are more than subsequent periods. It means that in the early periods, it is more possible that the affected country cannot handle situations properly, because of significant demands at first periods. Table 9 shows information about six periods and the number of levels in each period. According to this table during first, second and third level the government cannot satisfy evacuating demands properly, so international suppliers send their rescue vehicles to the affected areas, but they act independently, in another world this part of international suppliers is the leader in these periods, and the proposed model is a three-level model. During the fourth, fifth, sixth periods, when demands for evacuation decrease, the government can handle emergency suitably. It means the government needn't international suppliers' help, and he/she acts as the leader. So, the proposed model is a bilevel model for these periods. Table 11 summarizes the value of each objective function in each period.

Table 11

Objective functions of the proposed model in each period based on number of levels

\begin{tabular}{|c|c|c|c|c|c|c|}
\hline & & & \multicolumn{4}{|c|}{ Objective functions } \\
\hline Time period & & Leader of period & $\begin{array}{c}\text { Independent part } \\
\text { of international } \\
\text { suppliers' objec- } \\
\text { tive function }\end{array}$ & $\begin{array}{l}\text { The govern- } \\
\text { ment's first ob- } \\
\text { jective function }\end{array}$ & $\begin{array}{l}\text { The govern- } \\
\text { ment's second } \\
\text { objective func- } \\
\text { tion }\end{array}$ & $\begin{array}{l}\text { Dependent part of } \\
\text { international sup- } \\
\text { pliers' objective } \\
\text { function }\end{array}$ \\
\hline 1 & \multirow{3}{*}{ 它 } & \multirow{3}{*}{ independent part of international suppliers } & 38000 & 9948 & 259155 & 169281 \\
\hline 2 & & & 38000 & 3290 & 252908 & 163972 \\
\hline 3 & & & 21800 & 2632 & 222732 & 138322 \\
\hline 4 & \multirow{3}{*}{$\frac{1}{\partial} \stackrel{\vec{d}}{\sigma}$} & \multirow{3}{*}{ government of the affected area } & - & 4574 & 182583 & 104195 \\
\hline 5 & & & - & 1316 & 128702 & 64984 \\
\hline 6 & & & - & 658 & 63078 & 24079 \\
\hline
\end{tabular}

In this section, we explain the advantages of using multi-level programming when the government cannot manipulate the situations effectively and bi-level programming when the government can. Table 12 shows that for first three periods, when the proposed model is tri-level, considering only one level's point of view will improve its own objective function(s) but hugely worsen other levels objective functions. The proposed multi-level model established a trade-off between leader and followers' goals. Table 12 demonstrates the multi-level model performance is more reasonable since leader and followers' points of view are considered. Considering just one perspective generates extreme solutions while multi-level model presents reasonable and moderate solutions. In other words, the multi-level model results in equilibrium as $f_{\text {leader }} \leq f_{\text {multi-level }} \leq f_{\text {followers }}$ for the independent part of international suppliers and $f_{\text {follower }} \leq f_{\text {multi-level }} \leq f_{\text {leader }}$ for the government and dependent part of international suppliers. Note that in the first three periods leader is evacuation part of international supplier, the first follower is the government, and the second follower is distribution part of international suppliers. Figure 3 and Figure 4 are graphical representations of these four points of view performances.

As discussed above, for the second three periods, the proposed model has two levels. In this situation, the government of the affected area is the leader, and international suppliers as the follower send their relief commodities to the government's warehouses. Table 13 shows the values of the objective functions of the bi-level model in the second three periods from three different points of view. Figure 5 and Figure 6 are graphical representations of these three points of view performances.

Table 12

Objective functions of the proposed model from different points of view for first three periods.

\begin{tabular}{cccccc}
\hline & & Leader per- & First follower & Second follower & Multi-level per- \\
perspective & perspective & spective \\
\hline Leader & & 65900 & 203500 & 218700 & 97800 \\
First follower & First objective & 24321 & 8704 & 28712 & 15870 \\
& Second objective & 1539842 & 313690 & 1334279 & 734795 \\
Second follower & & 973632 & 899700 & 364211 & 471575 \\
\hline
\end{tabular}




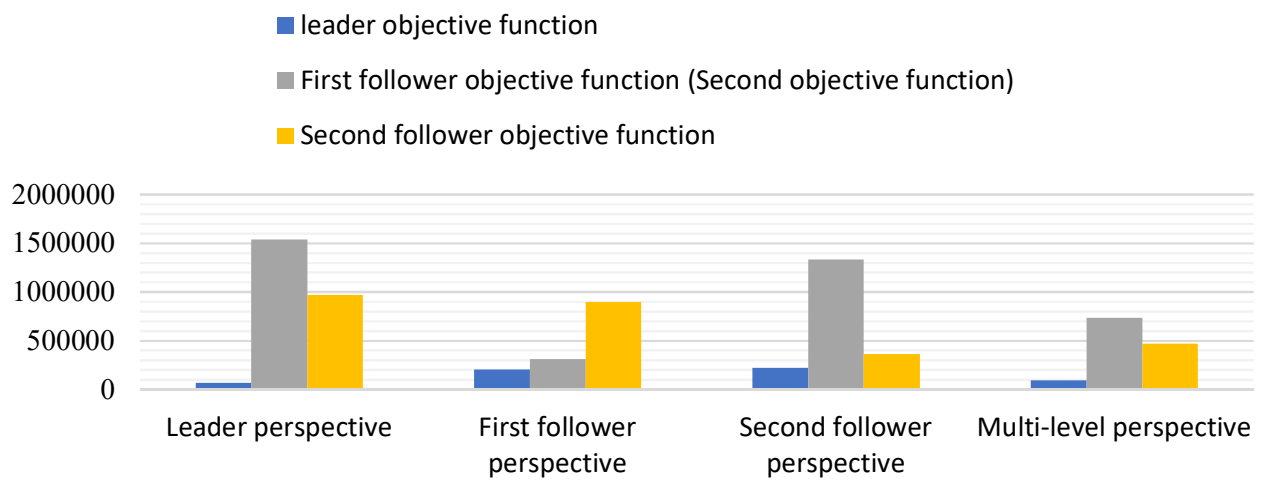

Fig. 3. objective functions of the proposed model from different points of view for first three periods

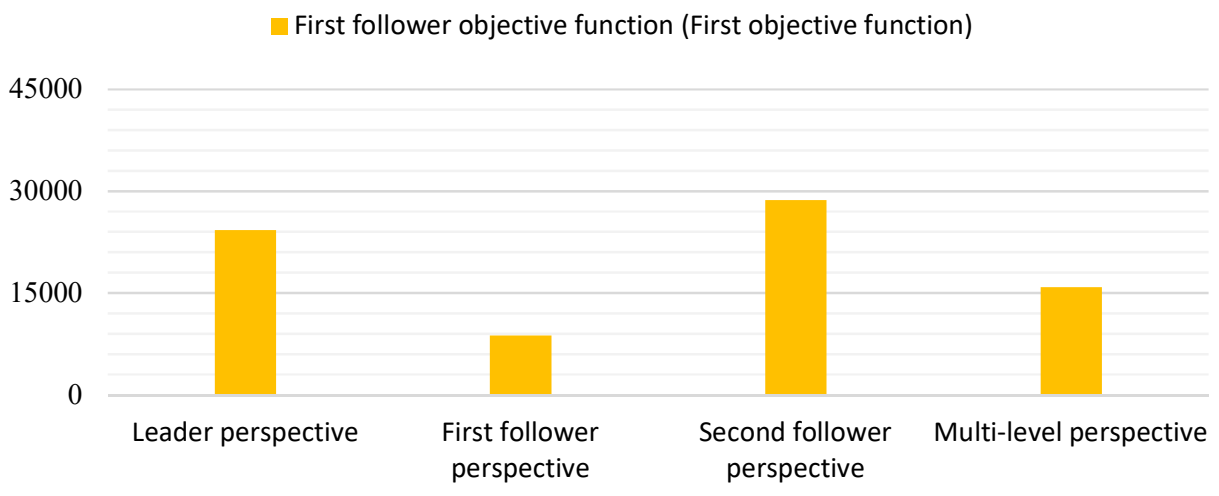

Fig. 4. the government's first objective function of the proposed model from different points of view for first three periods

As discussed above, for the second three periods, the proposed model has two levels. In this situation, the government of the affected area is the leader, and international suppliers as the follower send their relief commodities to the government's warehouses. Table 13 shows the values of the objective functions of the bi-level model in the second three periods from three different points of view. Figure 5 is the graphical representation of these three points of view performances.

\section{Table 13}

Objective functions of the proposed model from different points of view for second three periods

\begin{tabular}{llccc}
\hline & & Leader perspective & First follower perspective & Multi-level perspective \\
\hline \multirow{2}{*}{ Leader } & First objective function & 2913 & 13471 & 6548 \\
& Second objective function & 194590 & 794300 & 374363 \\
\hline Follower & & 425833 & 83021 & 193258 \\
\hline
\end{tabular}

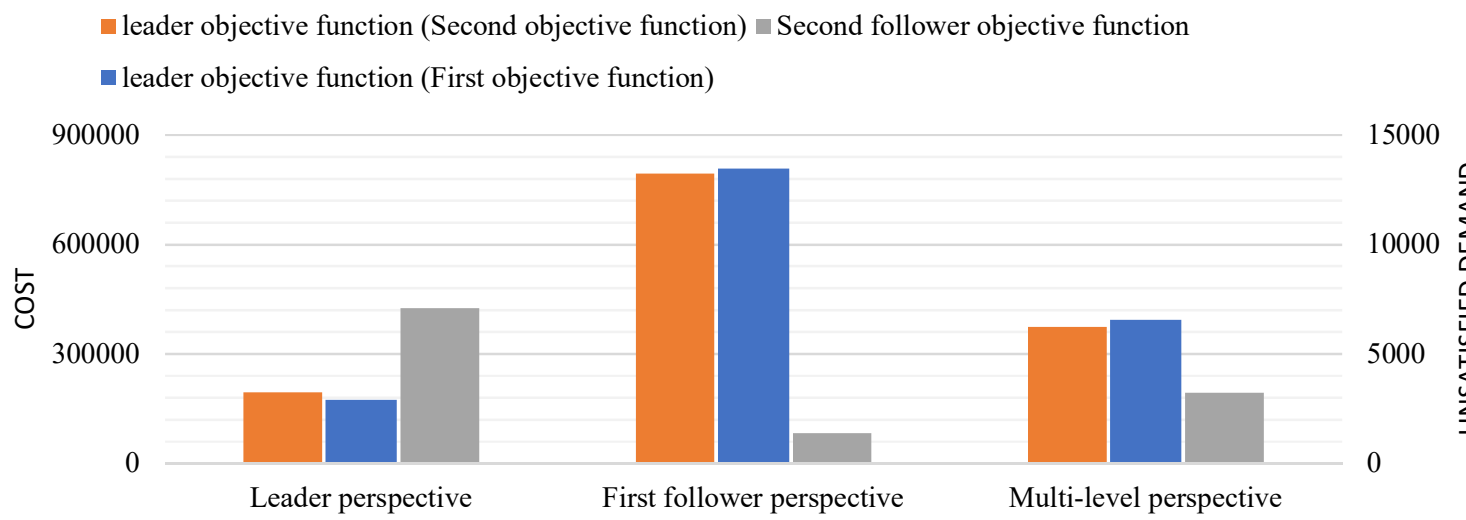

Fig. 5. objective functions of the proposed model from different points of view for second three periods 
In Table 12 and Table 13 comparison between each perspective against the best decision are made to show the advantages of using multi-level for the first three periods and bi-level model for the second three periods, respectively. According to Eq. (52) in Table 14 first, the amount of leader objective function in multi-level and followers-based models is compared with the leader's perspective objective function. Then the values of the government objective functions in the multi-level, leader, and the second follower are compared with the first follower's perspective objective functions. Finally, the same procedure is made for the second follower objective function. The multi-level solution increases all level objective functions but takes all decision-makers points of view into account. Table 15 displays the same information about the bi-level model for the second three periods. According to Camacho-Vallejo et al. (2015), the increases in objective functions derive from the following formula:

$$
\text { Increase }=\frac{\text { Current value }- \text { Best value }}{\text { Best value }}
$$

\section{Table 14}

Percentage of increase in the respective models against the best decision for the first three periods.

\begin{tabular}{cccccc}
\hline & & $\begin{array}{c}\text { Leader } \\
\text { perspective }\end{array}$ & $\begin{array}{c}\text { First follower } \\
\text { perspective }\end{array}$ & $\begin{array}{c}\text { Second follower } \\
\text { perspective }\end{array}$ & $\begin{array}{c}\text { Multi-level } \\
\text { perspective }\end{array}$ \\
\hline Leader & & - & 2.088012 & 2.318665 & 0.484067 \\
\hline First follower & First objective & 1.794233 & - & 2.298713 & 0.8233 \\
& Second objective & 3.908802 & - & 3.253495 & 1.342424 \\
\hline Second follower & & 1.673264 & 1.470271 & - & 0.294785 \\
\hline
\end{tabular}

\section{Table 15}

Percentage of increase in the respective models against the best decision for the second three periods

\begin{tabular}{lcccc} 
& & Leader perspective & $\begin{array}{c}\text { First follower per- } \\
\text { spective }\end{array}$ & $\begin{array}{c}\text { Multi-level per- } \\
\text { spective }\end{array}$ \\
\hline \multirow{2}{*}{ Leader } & First objective function & - & 3.624442 & 1.247854 \\
& Second objective function & - & 3.081916 & 0.923855 \\
Follower & & 4.12922 & - & 1.327821 \\
\hline
\end{tabular}

To show the benefits of the proposed multi-level model, we compute the gaps of the savings provided by this model against the leader and followers perspectives. The gaps appear in Table 16 and Table 17 for the first and second three periods, respectively. As Table 16 shows, by choosing the multi-level solution instead of the leader's perspective solution, we hugely reduce unsatisfied demands and the total costs of the government $53.25 \%$ and $109.56 \%$, respectively. We also decrease the transportation costs of the second follower $106.4 \%$. Then again, choosing the multi-level solution instead of the first follower's perspective gives us costs reduction by $108.07 \%$ for the leader and $90.78 \%$ for the second follower. Finally, using a multi-level solution instead of the second follower's perspective decreases leader objective function $123.61 \%$, and $80.92 \%$ and $81.58 \%$ in the first follower objective functions. In all cases, the reductions are more significant than the expected increase shown in Table 14. Table 17 shows the same information for the second three periods, which the government is the leader of the proposed model.

Table 16

Percentage of decrease provided by the multi-level model for the first three periods

\begin{tabular}{cccccc}
\hline & & $\begin{array}{c}\text { Leader per- } \\
\text { spective }\end{array}$ & $\begin{array}{c}\text { First follower per- } \\
\text { spective }\end{array}$ & $\begin{array}{c}\text { Second follower } \\
\text { perspective }\end{array}$ & $\begin{array}{c}\text { Multi-level } \\
\text { perspective }\end{array}$ \\
\hline Leader & & -0.32618 & 1.080777 & 1.236196 & - \\
\hline \multirow{2}{*}{ First follower } & First objective & 0.532514 & -0.45154 & 0.8092 & - \\
& Second objective & 1.095608 & -0.57309 & 0.815852 & - \\
\hline Second follower & & 1.064639 & 0.907862 & -0.22767 & - \\
\hline
\end{tabular}


Table 17

Percentage of decrease provided by the bi-level model for the second three periods

\begin{tabular}{ccccc}
\hline & & Leader perspective & First follower perspective & Multi-level perspective \\
\hline \multirow{2}{*}{ Leader } & First objective function & -0.55513 & 1.057269 & - \\
& Second objective function & -0.48021 & 1.121737 & - \\
\hline Follower & & 1.203443 & -0.57041 & - \\
\hline
\end{tabular}

\section{Conclusion}

In this paper, a dynamic leader-follower model for humanitarian logistics was presented in emergency situations to minimize total costs and unsatisfied demands of the government and shipping costs of international suppliers. This model determines decisions related to distribution and evacuation for a multiperiod network. To improve the application of the model against the lack of central authority, we presented a dynamic leader-follower model, which players changed their roles based on different situations. The results show that for the first three periods, when the government is not capable of handling demand for rescue operation in emergency situations, International suppliers become the leader. Thus, international supplier helps the government to evacuate injured people. However, by decreasing the demand for rescue operation in other periods, the government properly handles the rescue operation and acts as the leader and international supplier are obliged to obey the country law and act under its authority. In brief, our contributions can be summarized as follows:

(1) We developed a multi-level model to take different decision-makers into account. Because in an emergency situation, different decision-makers play in the game with different objective functions.

(2) the proposed model challenges the lack of central authority in an emergency situation. This model has a dynamical behavior which can change its levels in different periods based on various conditions.

Future studies can be aimed at new game conditions, such as considering local suppliers as a new follower. The local suppliers can facilitate the distribution and evacuation operation. Moreover, because of the uncertain nature of natural disasters, capturing this uncertainty will benefit decision-makers. In many studies demands for relief commodities, blood products, rescue operation are random. Therefore, to deal with the uncertainty, robust optimization can be used to extend the proposed model in this paper. In many cases, the government of the affected area do not accept other countries offers in emergency situation (mostly because of political constraints). Therefore, researchers can investigate the effects of political constraints on the proposed model using Monte-Carlo simulation.

\section{References}

Ahmadi, M., Seifi, A., \& Tootooni, B. (2015). A humanitarian logistics model for disaster relief operation considering network failure and standard relief time: A case study on San Francisco district. Transportation Research Part E: Logistics and Transportation Review, 75, 145-163.

Aksen, D., Aras, N., \& Piyade, N. (2013). A bilevel p-median model for the planning and protection of critical facilities. Journal of Heuristics, 19(2), 373-398.

Angelo, J. S., \& Barbosa, H. J. (2015). A study on the use of heuristics to solve a bilevel programming problem. International Transactions in Operational Research, 22(5), 861-882.

Arroyo, J. M., \& Galiana, F. D. (2005). On the solution of the bilevel programming formulation of the terrorist threat problem. IEEE transactions on Power Systems, 20(2), 789-797.

Barbarosoğlu, G., Özdamar, L., \& Cevik, A. (2002). An interactive approach for hierarchical analysis of helicopter logistics in disaster relief operations. European Journal of Operational Research, 140(1), 118-133.

Camacho-Vallejo, J. F., González-Rodríguez, E., Almaguer, F. J., \& González-Ramírez, R. G. (2015). A bi-level optimization model for aid distribution after the occurrence of a disaster. Journal of Cleaner Production, 105, 134-145. 
Chapman, A. G., \& Mitchell, J. E. (2018). A fair division approach to humanitarian logistics inspired by conditional value-at-risk. Annals of Operations Research, 262(1), 133-151.

Cozzolino, A. (2012). Humanitarian logistics: cross-sector cooperation in disaster relief management. Springer Science \& Business Media.

Feng, C., \& Wen, C. (2005). A bi-level programming model for allocating private and emergency vehicle flows in seismic disaster areas. In Proceedings of the Eastern Asia Society for Transportation Studies, Vol 5 (Vol. 5, pp. 1408-1423).

Fereiduni, M., \& Shahanaghi, K. (2016). A robust optimization model for blood supply chain in emergency situations. International Journal of Industrial Engineering Computations, 7(4), 535-554.

Fereiduni, M., \& Shahanaghi, K. (2017). A robust optimization model for distribution and evacuation in the disaster response phase. Journal of Industrial Engineering International, 13(1), 117-141.

Guha-Sapir, D., Vos, F., Below, R., \& Ponserre, S. (2011). Annual disaster statistical review 2010. Cent. Res. Epidemiol. Disasters.

Gutjahr, W. J., \& Dzubur, N. (2016). Bi-objective bilevel optimization of distribution center locations considering user equilibria. Transportation Research Part E: Logistics and Transportation Review, 85, 1-22.

Holguín-Veras, J., Jaller, M., Van Wassenhove, L. N., Pérez, N., \& Wachtendorf, T. (2012). On the unique features of post-disaster humanitarian logistics. Journal of Operations Management, 30(7-8), 494-506.

Jabbarzadeh, A., Fahimnia, B., \& Seuring, S. (2014). Dynamic supply chain network design for the supply of blood in disasters: A robust model with real world application. Transportation Research Part E: Logistics and Transportation Review, 70, 225-244.

Jahre, M., Persson, G., Kovács, G., \& Spens, K. M. (2007). Humanitarian logistics in disaster relief operations. International Journal of Physical Distribution \& Logistics Management, 37(2), 99-114.

John, L., \& Ramesh, A. (2016). Modeling the barriers of humanitarian supply chain management in India. In Managing humanitarian logistics (pp. 61-82). Springer, New Delhi.

Knott, R. (1987). The logistics of bulk relief supplies. Disasters, 11(2), 113-115.

Knott, R. P. (1988). Vehicle scheduling for emergency relief management: A knowledge-based approach. Disasters, 12(4), 285-293.

Kress, M. (2016). Humanitarian Logistics. In Operational logistics (pp. 137-144). Springer, Cham.

Losada, C., Scaparra, M. P., Church, R. L., \& Daskin, M. S. (2012). The stochastic interdiction median problem with disruption intensity levels. Annals of Operations Research, 201(1), 345-365.

Özdamar, L., Ekinci, E., \& Küçükyazici, B. (2004). Emergency logistics planning in natural disasters. Annals of operations research, 129(1-4), 217-245.

Rodríguez-Espíndola, O., Albores, P., \& Brewster, C. (2018). Disaster preparedness in humanitarian logistics: A collaborative approach for resource management in floods. European Journal of Operational Research, 264(3), 978-993.

Tatham, P., \& Christopher, M. (Eds.). (2018). Humanitarian logistics: Meeting the challenge of preparing for and responding to disasters. Kogan Page Publishers.

Van Wassenhove, L. N. (2006). Humanitarian aid logistics: supply chain management in high gear. Journal of the Operational research Society, 57(5), 475-489.

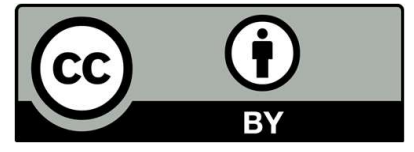

(C) 2020 by the authors; licensee Growing Science, Canada. This is an open access article distributed under the terms and conditions of the Creative Commons Attribution (CC-BY) license (http://creativecommons.org/licenses/by/4.0/). 